\title{
A Clinical Approach to Arterial Ischemic Childhood Stroke: Increasing Knowledge over the Last Decade
}

\author{
Maja Steinlin ${ }^{1}$ \\ ${ }^{1}$ Department of Neuropaediatrics, University Children's Hospital, \\ Bern, Switzerland \\ Neuropediatrics 2012;43:1-9.
}

Address for correspondence and reprint requests Prof. Dr. Maja Steinlin, Neuropaediatrics, University Children's Hospital, Inselspital, 3010 Bern, Switzerland (e-mail: maja.steinlin@insel.ch).

Stroke is a rare, but terrifying and devastating disease in childhood. Over the last two decades, childhood stroke is increasingly being recognized as an important cause of childhood morbidity and ranges among the top 10 causes of death in children. ${ }^{1-3}$ Thus childhood stroke is an important burden, not only for affected children and their families, but also for health insurances and socioeconomic reasons. The costs for pediatric stroke are substantial: In an North American study, the average cost of a childhood stroke admission was $\$ 81,869$, the average adjusted 5 years costs are $\$ 135,161 .^{4}$ International data suggest an incidence of childhood stroke of $\sim 2$ to $5 / 100,000$ children per year. ${ }^{1}$ Data from the Swiss Neuropediatric Stroke Registry suggest an inci- dence for arterial ischemic stroke (AIS) in childhood of 2.1/ 100,000 children per year. ${ }^{5}$ There is a suggestion of a higher incidence, due to clinically unrecognized events. ${ }^{6}$ For yet unknown reasons there is a worldwide male predominance in childhood stroke. ${ }^{7,8}$

Many excellent reviews have been published recently. ${ }^{1,9-12}$ There are three guidelines for treatment published. ${ }^{13-15}$ This article will not attempt to give a review of the subject, but will try to guide a physician through many aspects one has to consider, dealing with a child with acute arterial ischemic stroke, from emergency to the long-term follow-up and giving some inputs on differential diagnosis, work-up, and treatment as linked to the symptoms and received

April 18, 2011

accepted after revision

February 3, 2012
Copyright $\odot 2012$ by Thieme Medical Publishers, Inc., 333 Seventh Avenue, New York, NY 10001, USA. Tel: +1(212) 584-4662.
DOI http://dx.doi.org/ 10.1055/s-0032-1307449. ISSN 0174-304X. 
findings which might alert the physician to it. For clarification, the reader is asked to consult the summaries of risk factors and investigations in the given tables. The information of this paper is based on published studies or consensus papers, but in case of missing information the current proceedings at the University Children's Hospital in Bern including our own experience through the "Swiss Neuropaediatric Stroke Registry" (SNPSR) are described.

\section{The Problem of Delayed Diagnosis}

An important problem of childhood stroke is the delayed diagnosis. ${ }^{16-19}$ Missing awareness by parents and professionals of the possibility of a stroke already in children is a major concern. The second most important problem is the difficult differential diagnosis. Shellhaas et al $(2006)^{20}$ could show that $21 \%$ of children presenting with suspicion of stroke had a different disease, in $60 \%$ of them a "nonbenign" etiology like seizures of different origin, posterior leukoencephalopathy, vascular anomalies, autoimmune inflammatory problems, infectious disease like abscess or encephalitis, brain tumor, drug toxicity or idiopathic intracranial hypertension. . In contrary, Braun et al $(2006)^{21}$ could show that in 19/45 of the children presenting with ischemic stroke primary suspicion was a nonstroke etiology and that in 5/45 etiology of stroke had to be revised after diagnostic work-up. The mean interval from initial to final correct diagnosis was 7 days ( 3 hours to 7 years), the change of diagnosis led to therapeutic changes in 17 patients. Thus, any child presenting with history and/or symptoms which might be due to an arterial ischemic stroke, should get an immediate work-up, to prove or rule out this diagnosis.

\section{Signs and Symptoms at Manifestation}

One of the reasons for the difficult primary diagnosis of stroke is certainly the variable symptoms and signs at manifestation (-Fig. 1, SNPSR), which might occur at any age (-Fig. 2, SNPSR). Thus, in the following section presenting symptoms of stroke, their differential, and their possible link to risk factors of stroke are going to be discussed. This might help a physician in emergency to realize the possibility of stroke and to initiate fast the most important steps of investigations.

\section{Age at manifestation (SNPSR 2000-2009)}

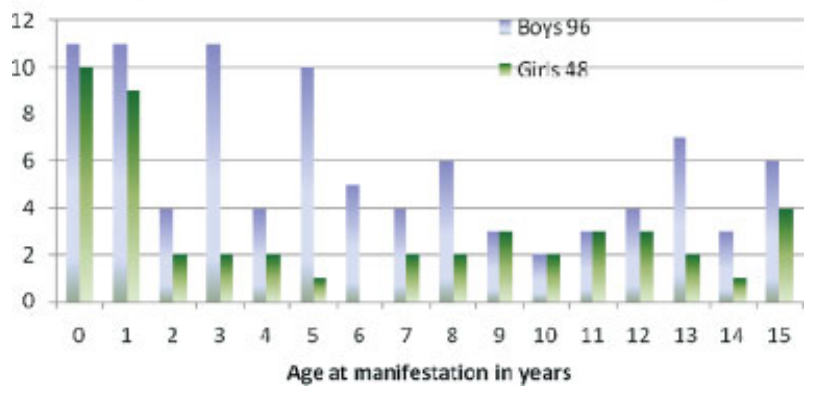

Figure 1 Age at manifestation of stroke (SNPSR).

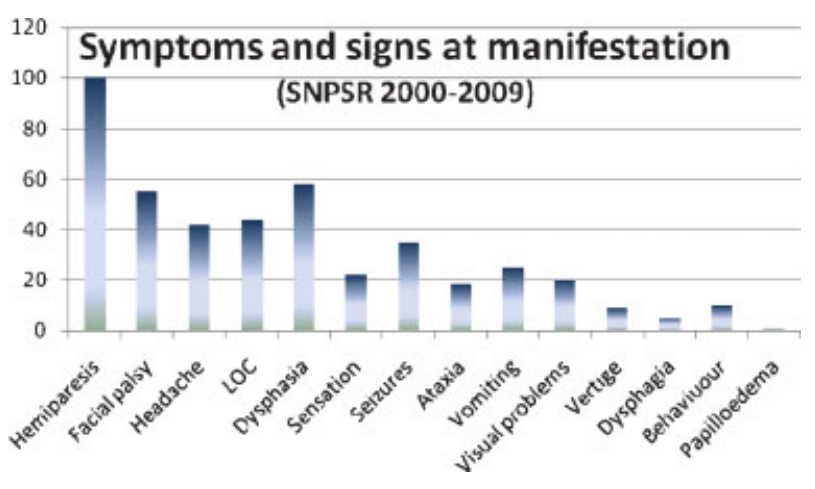

Figure 2 Symptoms at manifestation (SNPSR).

A total of 70 to $80 \%$ of the children present with hemiparesis, with or without facial palsy, or dysphasia. ${ }^{5}$ Dysphasia in childhood is not limited to stroke of the dominant side, most likely due to the immature lateralization of language. ${ }^{22}$ Focal signs and symptoms are usually related to the localization of the ischemic lesion, however one has to be aware that also children with isolated thalamic stroke might present with hemiplegia and/or dysphasia. In contrast, ataxia is a typical symptom of an infratentorial stroke, but not limited to cerebellar lesions. Some children show nonfocal symptoms as headache, vomiting, or change of level of consciousness. ${ }^{2,5}$ Headaches are present in $30 \%$ of children, before, with or shortly after the onset of symptoms. ${ }^{5,23}$ Most important differential diagnosis are certainly hemiplegic migraine or dissection of carotid or vertebral artery. For the diagnosis of hemiplegic migraine, family or personal history and careful evaluation of presenting symptoms are most helpful. Hemiplegic migraine typically presents with a Jacksonian march of symptoms, which is different to the sudden onset of symptoms due to ischaemia. ${ }^{24}$ In our experience: children with hemiplegic migraine are frightened by their neurological loss of functions, but stroke patients show an astonishing neglect to their severe symptoms. Occipital headaches in children might be the first symptom of a cerebellar stroke and/or extracranial dissection. In the presence of an extracranial dissection the children might complain about ipsilateral pain of neck or face, in the presence of intracranial dissection about half-sided headache. The pain related to dissections is usually violent, nonpulsating, and lasting for hours or days. The focal neurological symptoms encountered are typically supratentorial in cases of carotid dissection and infratentorial (like cranial nerve dysfunction, Horner syndrome, diplopia, swallowing problems) in cases of vertebral dissections, ${ }^{25,26}$ although Horner and cranial nerve palsy can also be present in case of a carotid dissection. ${ }^{27}$ The dissection and therefore the pain might precede the acute ischemia by days, transient ischemic symptoms as warning signs are frequent. Mild to moderate changes of level of consciousness are present in onethird of children with ischemic stroke. They differ from hemorrhagic stroke, where loss of consciousness and coma are much more frequent. ${ }^{21}$ Total $20 \%$ of children with stroke present seizures during the first hours or days after stroke. ${ }^{28,29}$ It is our experience that seizures more frequently 


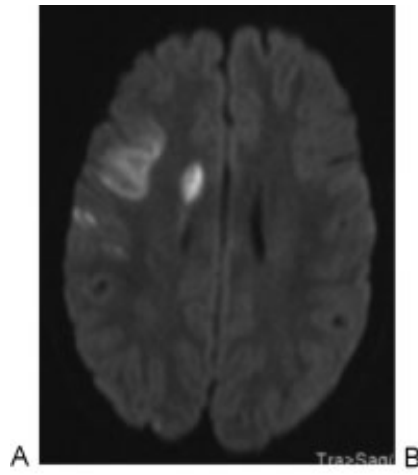

DWI (day 3)

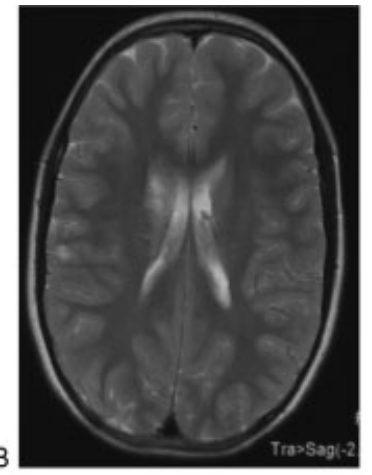

T2 (day 3)

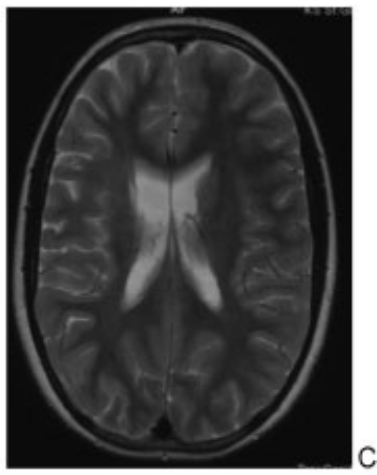

T2 FU after 4.5 years

Figure 3 MR imaging showing better visualization of subacute ischemic lesion at day 3 in DWI (A) than in T2 weighted images (B). Follow-up images (C) revealing ischemic sequelae 4.5 years after stroke corresponding to extension of primary DWI ischemic lesion at day 3.

occur during the first hours or days after the stroke, than actually at manifestation of the stroke, which is also supported by the paper of York-Corrales et $\mathrm{al}^{30}$. Age at time of stroke has an influence on possible symptoms: children $<1$ year are more likely to present with seizures and altered mental stage and children $>1$ year with focal neurological signs. $^{31}$

\section{Neuroimaging}

The multifarious symptoms and the difficulties in diagnosis point to the importance of neuroimaging in a child with suspicion of childhood stroke, not only for diagnostic purposes, but also for evaluation of etiology and outcome. ${ }^{32,33}$ Computed tomography has the advantage of being readily available in emergency, but the disadvantage of missing out on early, small, or infratentorial ischemia. The golden standard is certainly magnetic resonance imaging with diffusion weighted images, revealing the ischemia within minutes and giving early on an accurate measure of the extension of ischemic area ( - Fig. 3). T1, T2, and gradient echo sequences supplement the initial investigation. ${ }^{34}$ Early MRI with its diffusion and perfusion-weighted sequences is not only useful to detect ischaemia, but also for the differential diagnosis of many mimics of childhood stroke as acute demyelinating encephalopathy and hemiplegic migraine. Although $\mathrm{CT}$ is the emergency image of choice to search for a hemorrhage, acute hemorrhage can also be detected by MRI. Early MR also gives the opportunity to detect vasculopathies by a MR angiography (-Fig. 4). This is important in view of recent data showing that $53 \%$ of children with arterial ischemic stroke show arteriopathies, ${ }^{12}$ Inclusion of the neck vessels for imaging is

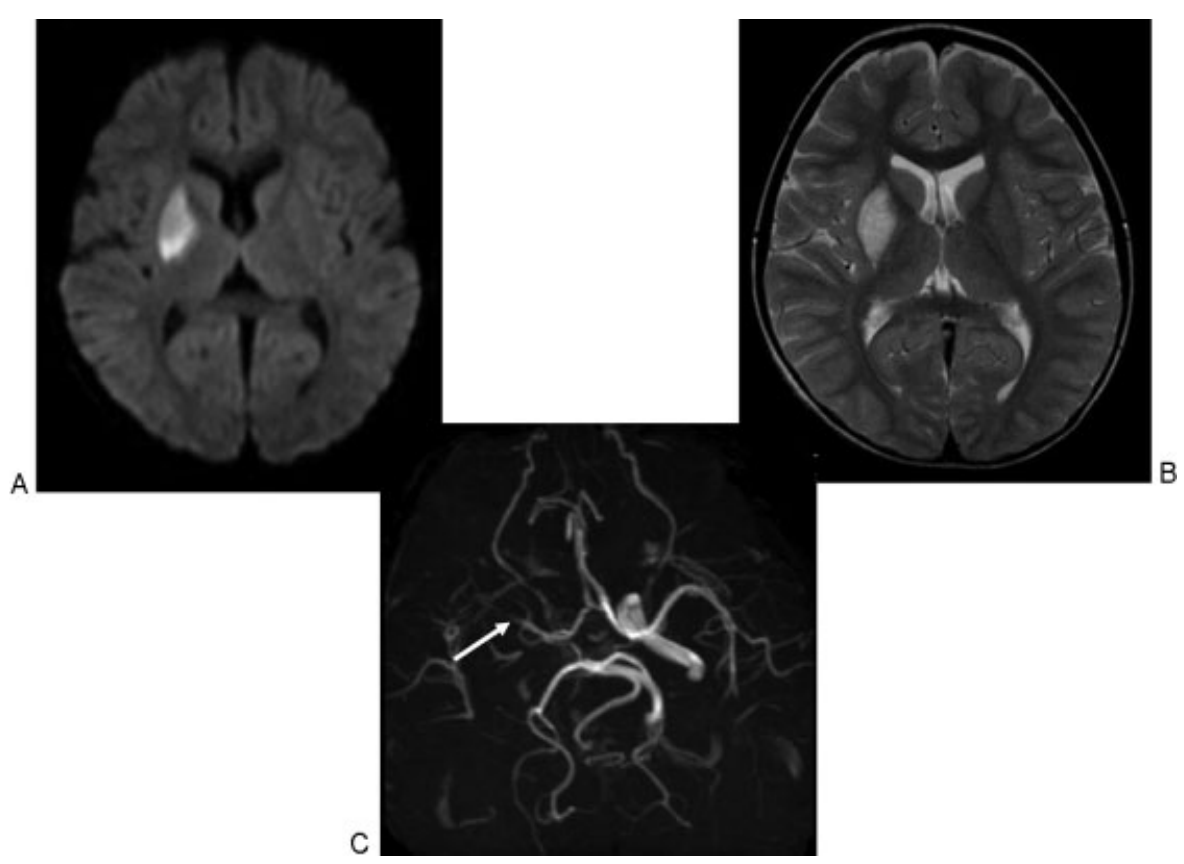

Figure 4 A 5-year-old boy presenting with acute hemiparesis left sided. The axial DWI (A) and T2 weighted (B) images show a subacute ischemic lesion of basal ganglia right-sided. (C) MR angiography demonstrates occlusion of M1 segment of medial cerebral artery. 

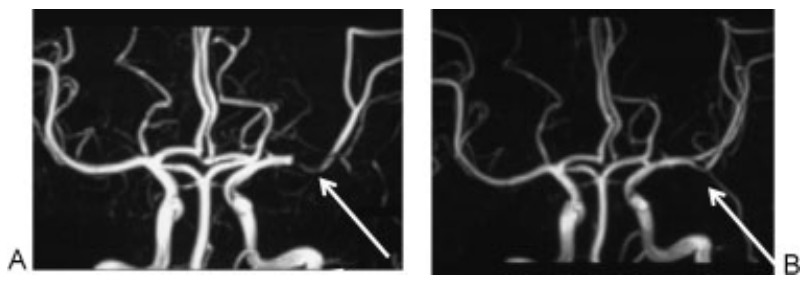

Figure 5 A 15-year-old boy presenting with acute right-sided hemiplegia. MR angio reveals severe stenosis of left sided medial cerebral artery (A) with significant recanalization 6 months later (B).

requested, as $25 \%$ of the children show lesions of cervical vessels $^{34}$ Best sequences for detection of dissections are a combination of (contrast-enhanced) MRA and nonfat and fat suppressed T1 weighted images of cervicocranial vessels. ${ }^{35}$ In view of the frequency of arteriopathy CT angiography might be equal to MR angiography, but both are known to miss the information from fat suppressed images. ${ }^{8,36}$ Vascular ultrasounds is missing $\sim 20 \%$ of dissections, ${ }^{37}$ but is an easy method for following up on vasculopathies. More accurate information for follow-up is available by MR angiography (-Fig. 5). Although conventional angiography is still the gold standard for detecting dissections and vasculitis, it is rarely performed in childhood stroke and has its indication for specific questions or in cases of endovascular treatments.

\section{Risk factors}

Published data over the last two decades have revealed that AIS has different etiological characteristics in children than in adults. ${ }^{1,3,5,10,12}$ Knowledge on childhood AIS risk factors has grown considerably in recent years and it has been shown that childhood stroke is a multiple risk problem. ${ }^{1,5}$ - Table 1 gives an overview on the many reported risk factors in childhood stroke, the leading symptoms, and primary investigations. However, knowledge of relationship between the various risk factors is still very limited, thus an evidencebased understanding of optimal treatment is still missing. ${ }^{10}$

Arteriopathies can be detected in about half of the children after stroke. ${ }^{11,12,38-40}$ A total of $32 \%$ consist of the above discussed focal cerebral arteriopathy (FCA) related to infection or postvaricella syndrome. A total of $22 \%$ are due to arterial dissection. Beside infection other triggers do play a role in its occurrence: the most frequent is a (bagatelle-) trauma, but others such as cervical manipulation or skeletal abnormalities, homocysteinaemia and MTHRF mutations, connective tissue disease as Marfan syndrome, and migraine are also reported. ${ }^{25,41-43}$ Moyamoya (primary or secondary) is responsible for another $22 \%$ of arteriopathies and is the etiology of $\sim 6 \%$ of childhood arterial ischemic stroke. ${ }^{38,44}$ It is characterized by progressive stenosis of the apices of intracranial internal carotid involving anterior and medial cerebral artery. Secondary Moyamoya can be seen in children with sickle cell disease, neurofibromatosis, and Down syndrome. The frequency of sickle cell disease in a childhood stroke population depends on the geographical area. In continental Europe sickle cell disease is rare. However, due to the possible prophylactic treatment it is important to detect early. ${ }^{23}$ Primary arteritis of the central nervous system (PACNS) was thought to be rare, however recent work from Bensler et $\mathrm{al}^{45}$ suggests it to be underdiagnosed. Nonprogressive medium to large PCNS might be one of the etiologies for transient focal arteriopathies. Typically it shows by a stenosis of proximal medial cerebral artery with gadolinium enhancing wall thickening. CSF opening pressure is elevated, but cells and protein normal. Infectious etiology, especially varicella, has to be considered. Progressive medium to large vessel PACNS manifest by preceding symptoms as headache, cognitive dysfunction, and behavioral changes followed secondarily by a focal stroke. Imaging findings are similar to the none progressive medium to large vasculitis, but involve proximal and distal arteries and might include several vessel beds. Bilateral lesions are rare. Opening pressure of CSF is elevated, but in this form cells (lymphocytes) and protein are usually elevated. Small vessel CNS vasculitis is the classical form of PACNS with slowly progressive symptoms and the typical laboratory findings of vasculitis.

For children important risk factors are infectious and parainfectious etiologies. ${ }^{5,46,47}$ Major infections such as sepsis and meningitis have long been recognized as risk factors for stroke. However, over the last two decades more and more reports on minor infections related to stroke have been published. Besides Varicella ${ }^{48,49}$ other pathogens as Borrelia, mycoplasma, enterovirus, and parvovirus ${ }^{1}$ are also thought to provoke cerebral ischemia. One of the important pathophysiology for infection triggered ischemia might be transient FCA. The current understanding is that a parainfectious reaction leads to a focal arteriopathy, as it is shown in a case of varicella zoster related focal arteriitis. ${ }^{50}$ Recently, upper respiratory infections have been related to this transient arteriopathy, further supporting the parainfectious etiology. ${ }^{46}$ More and more information points to the idea, that an inflammatory reaction plays an important role in idiopathic childhood stroke. ${ }^{51,52}$ The most frequent etiology related to FCA is sickle cell disease, altered inflammation signaling plays an important role too. ${ }^{53}$ In addition, acute infection is shown to be a risk factor and potential trigger for spontaneous cervical artery dissection. $^{42}$

The second most important risk factor for childhood stroke are cardiac problems. ${ }^{1,5}$ Peri-interventional insults remain frequently undetected, but catheter interventions have a significant risk of stroke. ${ }^{54}$ During heart operations, but especially during the days after the operation, children are at high risk for an embolic complication. Also for strokes related to cardiac problems co-risk factors as elevated lipoprotein a, MTHRF mutation, homocysteinemia, hereditary coagulopathies, or infections might be detected.

Rare, but important for a pediatric population are metabolic infarctions. ${ }^{55,56}$ Energy depletion leads to ischemic lesions in mitochondrial problems. In urea cycle disorders (especially OTC), toxic deposits lead to destruction of cerebral tissue. For this reason, metabolic infarctions do not occur in a vascular territory, MELAS for example shows a predilection for occipital infarctions. Other metabolic problems such as Fabry disease lead to a focal arteriopathy, metabolic disorders 
Table 1 Risk Factors and Investigations in Childhood Stroke (Second Variant)

\begin{tabular}{|c|c|c|}
\hline Summary of Risk Factors & Symptomatic Key & Diagnostic Investigations \\
\hline \multicolumn{3}{|l|}{ Cardiac Problems } \\
\hline $\begin{array}{l}\text { Congenital malformations, } \\
\text { cardiomyopathy }\end{array}$ & $\mathrm{PH}$, clinical examination & Echocardiography, ECG \\
\hline Endocarditis & $\begin{array}{l}\text { General condition, fever, } \\
\text { microemboli }\end{array}$ & Blood cultures, echocardiography \\
\hline \multicolumn{3}{|l|}{ Vasculopathy } \\
\hline Moyamoya & Recurrent episodes & MR-angiography, vascular sonography \\
\hline Fibromuscular dysplasia & High blood pressure & \\
\hline Arterial dissection & Minor trauma, infectionb & $\begin{array}{l}\text { MR-angiography, fat suppressed MR-imaging, } \\
\text { vascular sonography }\end{array}$ \\
\hline Transient focal arteriopathy & $\begin{array}{l}\text { Varicella, Borrelia, viral } \\
\text { infection }\end{array}$ & $\begin{array}{l}\text { MR-angiography, infection + vasculitis parameter, } \\
\text { serologies }\end{array}$ \\
\hline \multicolumn{3}{|l|}{ Vasculitis } \\
\hline $\begin{array}{l}\text { Nonprogressive medium to } \\
\text { large vasculitis }\end{array}$ & Acute stroke & $\begin{array}{l}\text { CSF opening pressure MR with focal enhancing } \\
\text { vasculopathy }\end{array}$ \\
\hline $\begin{array}{l}\text { Progressive medium to large } \\
\text { vasculitis }\end{array}$ & $\begin{array}{l}\text { Progressive symptoms } \\
\text { followed by acute stroke }\end{array}$ & $\begin{array}{l}\text { CSF opening pressure, cells and protein MR with } \\
\text { focal enhancing vasculopathy }\end{array}$ \\
\hline $\begin{array}{l}\text { Lupus, antiphospholipid-AB } \\
\text { syndrome, systemic } \\
\text { diseases, ZNS-vasculitis, } \\
\text { others }\end{array}$ & Clinical symptoms & $\begin{array}{l}\text { Elevated BSR, pathological coagulation (aPPT), } \\
\text { lupus } A C \text {, anticardiolipin } A B, A N C A \text {, other } A B, M R I \text {, } \\
\text { MR-angio, SPECT }\end{array}$ \\
\hline \multicolumn{3}{|c|}{ Coagulopathies/Hematological Problems } \\
\hline Hereditary coagulopathy & $\mathrm{FH}$ and $\mathrm{PH}$, risk situation & $\begin{array}{l}\text { Level } 1 \text { testing: factor } \mathrm{V} \text { (Leiden), pro-thrombin, } \\
\text { protein } \mathrm{C} \text {, protein } \mathrm{S} \text {, homo-cyestein, lipoprotein } \mathrm{A} \text {, } \\
\text { factor VIII level } 2 \text { testing: fibrinogen, factor IX+ XI }\end{array}$ \\
\hline $\begin{array}{l}\text { Lupus-/antiphospholipid-AB- } \\
\text { syndrome }\end{array}$ & Clinical findings & Anticardiolipin-AB, lupus anticoagulants \\
\hline CDG-syndrome & $\begin{array}{l}\text { Retinitis pigmentosa, } \\
\text { dysmorphic } \\
\text { features }\end{array}$ & Transferrin electrophoresis, MRI \\
\hline Sickle cell anemia & Splenomegaly, anemia & Electrophoresis of hemoglobin, vascular ultrasound \\
\hline Anemia, Iron deficiency & Paleness & Red blood count, ferritin \\
\hline \multicolumn{3}{|c|}{ Connective Tissue Diseases and Metabolic Problems } \\
\hline Ehlers-Danlos-syndrome & $\begin{array}{l}\text { Hyperlaxity articulations } \\
\text { and skin }\end{array}$ & DNA, skin biopsy \\
\hline Marfan-syndrome & FH, marfanoid habitus & DNA, echocardiography \\
\hline $\begin{array}{l}\text { Mitochondrial problems } \\
\text { (MELAS) }\end{array}$ & $\begin{array}{l}\text { FH, failure to trith, } \\
\text { multiorgan problem, } \\
\text { occipital infarctions }\end{array}$ & $\begin{array}{l}\text { Lactate (blood, CSF), mDNA, enzymes } \\
\text { In muscles and skin }\end{array}$ \\
\hline Urea metabolic disorder & $\begin{array}{l}\text { Acute/fluctuant } \\
\text { neurological symptoms }\end{array}$ & $\mathrm{AA}, \mathrm{OA}$, ammonium \\
\hline $\begin{array}{l}\text { Molybdenum cofactor } \\
\text { deficiency }\end{array}$ & seizures & Sulfite test in urine, $A A$ in urine + serum, $O A$ in urine \\
\hline Homocystinuria & Marfanoid habitus & AA in urine \\
\hline Aminoacidemia & $\begin{array}{l}\text { Acute or remittent } \\
\text { neurological symptoms }\end{array}$ & AA (urine, serum, CSF) \\
\hline CDG-syndrome & See above & Transferrin electrophoresis \\
\hline Glutaric acidemia type I & $\begin{array}{l}\text { Macrocephaly, } \\
\text { hypoplasia temporal lobe }\end{array}$ & OA in urine, Tandem (carnitine profile) serum \\
\hline
\end{tabular}


Table 1 (Continued)

\begin{tabular}{|l|l|l|}
\hline Summary of Risk Factors & Symptomatic Key & Diagnostic Investigations \\
\hline Neurocutaneous Disorders & Skin, typical signs & Clinical criteria for diagnosis, DNA \\
\hline Neurofibromatosis & Skin & MRI \\
\hline Sturge-Weber-syndrome & \multicolumn{2}{|l|}{} \\
\hline Arteriosclerosis & Skin, typical symptoms & Alphagalactosidase activity, DNA \\
\hline Fabry disease & See above & Homocysteine (urine, blood), DNA \\
\hline Homocystinuria, ischemia & Clinic & Clinical diagnosis \\
\hline Syndromes of progeria & Atheromas, arcus lipemic & Electrophoresis of lipids \\
\hline Dyslipoproteinemia & \multicolumn{2}{|l}{} \\
\hline Medications & Drug screening \\
\hline $\begin{array}{l}\text { Heroin, cocaine, } \\
\text { sympathomimetic }\end{array}$ & History & \\
\hline Migraine & FH, PH &
\end{tabular}

$\mathrm{AA}$, amino acids; $\mathrm{OA}$, organic acids; $\mathrm{AB}$, antibodies; $\mathrm{CDG}$, carbohydrate deficient glycoprotein-syndrome; $\mathrm{FH}$, family history; $\mathrm{PH}$, personal history.

might also lead to cardiomyopathy or rhythmic problem, which in turn might provoke an embolic ischemia.

The risk for stroke in children is increased by the presence of additional factors such as hereditary coagulopathy. ${ }^{57-60}$ The most relevant are antithrombin deficiency, protein $C$ deficiency, elevated lipoprotein A, and antiphospholipid antibodies. Combination of the presence of hereditary coagulopathies doubles the risk of stroke.

In the last few years, more and more evidence has been detected that also iron deficiency or low ferritin might increase the risk of stroke. ${ }^{61}$ Preschool children are known to have an iron deficiency in 4 to $6 \%$. Therefore, beside frequent infections, iron deficiency might be an explanation why preschool children have a high risk of arterial ischemic stroke.

\section{Investigations}

Although in the majority one or more risk factors for stroke in childhood can be detected, ${ }^{5}$ more exact pathophysiological knowledge, especially on interference of different risk factors is still not present. Thus, a thorough course of investigations in each child after AIS is suggested.

Neuroimaging is the first investigation. Special attention has to be drawn to perform all necessary sequences and to image not only head, but also neck (see above). Vascular ultrasound is an easy investigation to follow on known arteriopathies with stenosis, but has a limitation for detection especially for dissections.

A cardiac investigation with electrocardiogram to look for rhythmic abnormalities and an echocardiography to search for structural or functional abnormalities is mandatory. Whether children need beside a transthoracic echocardiography also a transesophageal echo is still a matter of discussion. A recent paper shows the limitation for transthoracic echocardiography including bubble echo's to detect a foramen ovale with a sensitivity of $88 \%{ }^{62}$
As pediatric stroke is a multiple risk problem, laboratory investigations should be performed on a broad basis, including always search for infections, vasculitis, thrombophilia, and metabolic problems. - Table 2 gives a suggestion, on how to proceed with the necessary laboratory investigations.

\section{Controversies on Treatment}

Up to date, there are three guidelines on management of acute stroke in childhood. ${ }^{13-15}$ However, all three guidelines are not based on data from pediatric studies, but rather represent expert opinions or conclusions that have been drawn from adult studies. There is a broad agreement between professional about supportive treatment within the first few days: careful monitoring with body temperature $<36.5^{\circ} \mathrm{C}$, blood pressure adjusted to cerebral needs, treatment of dyselectrolytemia, hypoglycemia, and seizures. Especially in children with large volume and/or infratentorial ischemia, there is a high risk of malignant swelling. Early decompressive surgery has to be evaluated in these children, ${ }^{63,64}$ thus careful monitoring on an intensive care unit in these children is mandatory. Thrombolysis is shown to be feasible and successful in children. ${ }^{65,66}$ However, there is still missing evidence, that outcome of children can be influenced positively by this potentially also harmful treatment. There are few case reports, where children were successfully treated endovascularly by recanalization devices. ${ }^{67}$ The main discussion on acute treatment is heparinization versus aspirin. In the UK and American guidelines aspirin ( 3 to $5 \mathrm{mg} / \mathrm{kg} \mathrm{BW}$ ) is the treatment of choice, except for some special indications as cardiac embolism or extracranial dissection. In the chest guidelines heparinization during the acute phase till exclusion of cardiac problem or dissection is preferred over initial aspirin. In a study from Colorado and Germany, it was shown that anticoagulation during the first 4 weeks in children with arteriopathy (exclusion of Moyamoya) might be safe and worthwhile an evaluation. ${ }^{68}$ In an international 
Table 2 Investigations

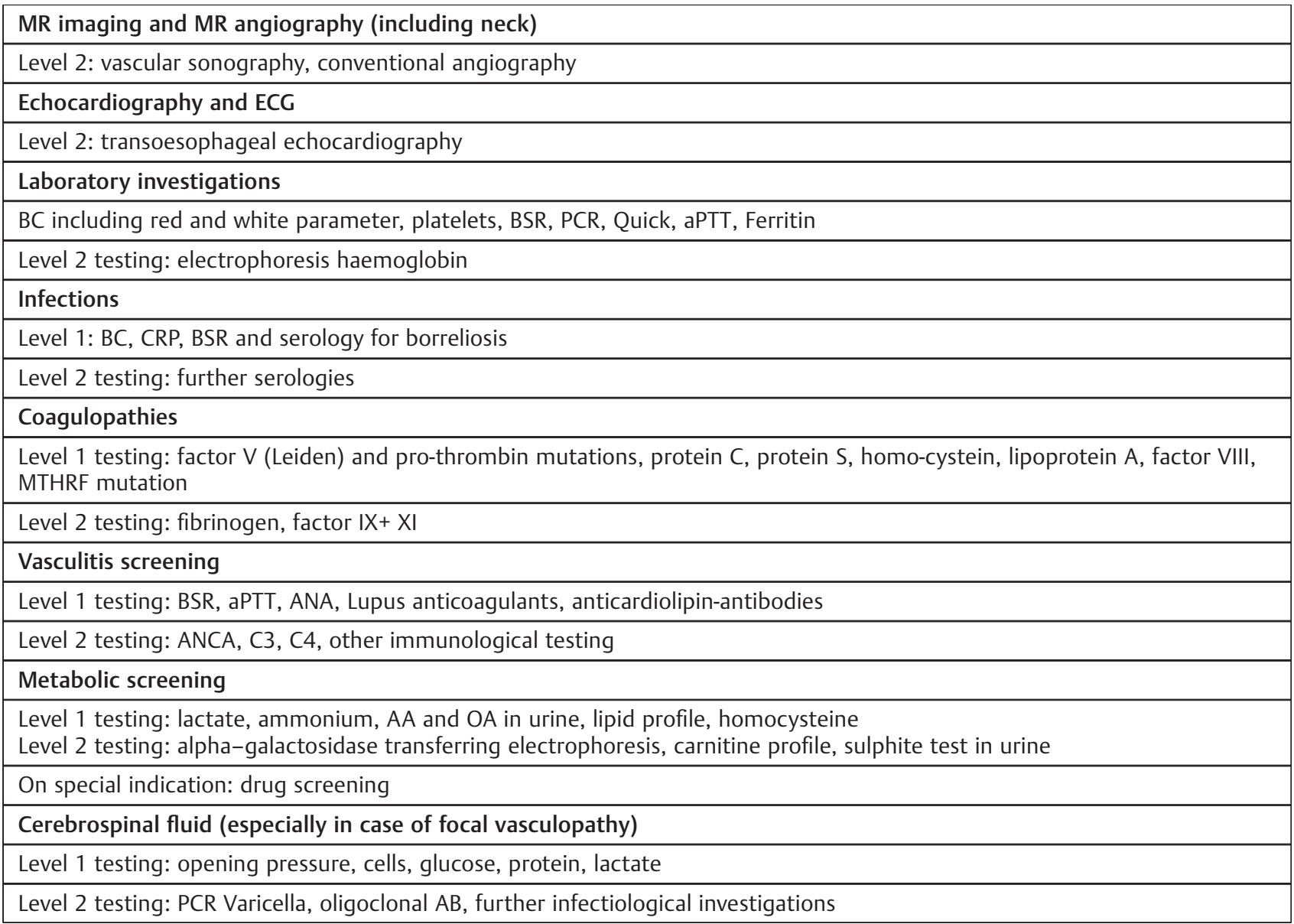

observational study, the variety of practical approaches in treatment decisions all over the world have been illustrated. ${ }^{69}$ Aspirin in a dosage of 2 to $3 \mathrm{mg} / \mathrm{kg}$ BW for prophylactic treatment after the acute phase is accepted by most professionals.

\section{Outcome and Prognosis}

For many decades, it was assumed that stroke in childhood is less devastating in children than in adults, concerning not only initial manifestation but also outcome. However, our recent study reveals that severity and outcome of arterial ischemic stroke in children and young adults (up to 40 years) are similar. ${ }^{70}$ Mortality in children is around 10 to $20 \%{ }^{3,5,71}$ In two-thirds of the children, lifelong handicap has to be expected. There are neurological residual symptoms in twothirds of children. ${ }^{69,71,79,80}$ In the majority, these consist of hemiparesis with and without facial involvement and/or dysphasia; but ataxia, ophthalmological problems, seizures, and many more are also reported. However, most pronounced for these children and their families are lifelong neurocognitive and behavior problems. ${ }^{72-75}$ There is still only limited knowledge on prognostic factors for outcome. It has been shown that the long-standing believe that younger children have better prognosis has to be revised. ${ }^{74,75}$ Neuroimaging might play a major role for prognosis, but knowledge is still limited. ${ }^{32,33,76}$ The burden of possible recurrence of stroke should not be neglected. Risk of recurrence is between 10 and $20 \%{ }^{39,77}$

In summary, there are many areas of limited knowledge and controversies in childhood arterial ischemic stroke. ${ }^{78}$ There is an urgent need of international and multicenter studies to gain knowledge, not only on treatment options, but also on natural course of the disease and prognostic factors.

\section{Acknowledgments}

I would like to thank Professor Gerhard Schroth, Department of Neuroimaging, University Hospital Bern, for providing the illustrations and Monica Knoll for help in preparation of the manuscript. I would also like to thank all the children and parents of the Swiss Neuropediatric Stroke Registry for helping to increase our knowledge of childhood stroke.

\section{References}

1 Amlie-Lefond C, Sébire G, Fullerton HJ. Recent developments in childhood arterial ischaemic stroke. Lancet Neurol 2008;7 (5):425-435

2 Lynch JK, Hirtz DG, DeVeber G, Nelson KB. Report of the National Institute of Neurological Disorders and Stroke workshop on perinatal and childhood stroke. Pediatrics 2002;109(1):116-123 
3 Mallick AA, Ganesan V, O'Callaghan FJ. Mortality from childhood stroke in England and Wales, 1921-2000. Arch Dis Child 2010;95 (1):12-19

4 Gardner MA, Hills NK, Sidney S, Johnston SC, Fullerton HJ. The 5-year direct medical cost of neonatal and childhood stroke in a population-based cohort. Neurology 2010;74(5):372-378

5 Steinlin M, Pfister I, Pavlovic J, et al; Swiss Societies of Paediatric Neurology and Neonatology.The first three years of the Swiss Neuropaediatric Stroke Registry (SNPSR): a population-based study of incidence, symptoms and risk factors. Neuropediatrics 2005;36(2):90-97

6 Agrawal N, Johnston SC, Wu YW, Sidney S, Fullerton HJ. Imaging data reveal a higher pediatric stroke incidence than prior US estimates. Stroke 2009;40(11):3415-3421

7 Golomb MR, Fullerton HJ, Nowak-Gottl U, Deveber G; International Pediatric Stroke Study Group. Male predominance in childhood ischemic stroke: findings from the international pediatric stroke study. Stroke 2009;40(1):52-57

8 Tan MA, DeVeber G, Kirton A, Vidarsson L, MacGregor D, Shroff M. Low detection rate of craniocervical arterial dissection in children using time-of-flight magnetic resonance angiography: causes and strategies to improve diagnosis. J Child Neurol 2009;24(10):12501257

9 Bernard TJ, Goldenberg NA. Pediatric arterial ischemic stroke. Hematol Oncol North Am 2010;24:167-80

10 Bernard TJ, Goldenberg NA. Pediatric arterial ischemic stroke. Pediatr Clin North Am 2008;55(2):323-338, viii

11 Fox CK, Fullerton HJ. Recent advances in childhood arterial ischemic stroke. Curr Atheroscler Rep 2010;12(4):217-224

12 Mackay MT, Wiznitzer M, Benedict SL, Lee KJ, Deveber GA, Ganesan V; International Pediatric Stroke Study Group.Arterial ischemic stroke risk factors: the International Pediatric Stroke Study. Ann Neurol 2011;69(1):130-140

13 Monagle P, Chan A, Massicotte P, et al. Antithrombotic therapy in children: the Seventh ACCP Conference on Antithrombotic and Thrombolytic Therapy. Chest 2004;126:645-687S

14 Roach ES, Golomb MR, Adams R, et al; American Heart Association Stroke Council ; Council on Cardiovascular Disease in the Young. Management of stroke in infants and children: a scientific statement from a Special Writing Group of the American Heart Association Stroke Council and the Council on Cardiovascular Disease in the Young. Stroke 2008;39(9):2644-2691

15 Royal College of Physicians, Pediatric Stroke Working Group. Stroke in childhood: clinical guidelines for diagnosis, management and rehabilitation. 2004

16 Martin C, von Elm E, El Koussy M, Boltshauser E, Steinlin M. Delayed diagnosis of acute ischemic stroke in children: a registry based study in Switzerland. Swiss Med Wkly 2011;19141w 13281

17 McGlennan C, Ganesan V. Delays in investigation and management of acute arterial ischaemic stroke in children. Dev Med Child Neurol 2008;50(7):537-540

18 Rafay MF, Pontigon AM, Chiang J, et al. Delay to diagnosis in acute pediatric arterial ischemic stroke. Stroke 2009;40(1):58-64

19 Srinivasan J, Miller SP, Phan TG, Mackay MT. Delayed recognition of initial stroke in children: need for increased awareness. Pediatrics 2009;124(2):e227-e234

20 Shellhaas RA, Smith SE, O'Tool E, Licht DJ, Ichord RN. Mimics of childhood stroke: characteristics of a prospective cohort. Pediatrics 2006;118(2):704-709

21 Braun KP, Kappelle LJ, Kirkham FJ, Deveber G. Diagnostic pitfalls in paediatric ischaemic stroke. Dev Med Child Neurol 2006;48 (12):985-990

22 Everts R, Lidzba K, Wilke M, et al. Strengthening of laterality of verbal and visuospatial functions during childhood and adolescence. Hum Brain Mapp 2009;30(2):473-483

23 Adams RJ, McKie VC, Hsu L, et al. Prevention of a first stroke by transfusions in children with sickle cell anemia and abnormal results on transcranial Doppler ultrasonography. N Engl J Med 1998;339(1):5-11

24 Thompson JK. Diagnosis of head pain: an idiographic approach to assessment and classification. Headache 1982;22(5):221-232

25 Fullerton HJ, Johnston SC, Smith WS. Arterial dissection and stroke in children. Neurology 2001;57(7):1155-1160

26 Rafay MF, Armstrong D, Deveber G, Domi T, Chan A, MacGregor DL Craniocervical arterial dissection in children: clinical and radiographic presentation and outcome. J Child Neurol 2006;21(1): 8-16

27 Krasravi N, Leung A, Silver I, Burneo JG. Dissection of the internal carotid artery causing Horner syndrome and palsy of nerve XII. CMAJ 2010;15:182

28 Abend NS, Beslow LA, Smith SE, et al. Seizures as a presenting symptom of acute arterial ischemic stroke in childhood. J Pediatr 2011;159(3):479-483

29 Shing RK, Zecavati N, Shing J, et al. Seizures in childhood stroke. J Pediatr 2011

30 Yock-Corrales A, Mackay MT, Mosley I, Maixner W, Babl FE. Acute childhood arterial ischemic and hemorrhagic stroke in the emergency department. Ann Emerg Med 2011;58(2):156-163

31 Zimmer JA, Garg BP, Williams LS, Golomb MR. Age-related variation in presenting signs of childhood arterial ischemic stroke. Pediatr Neurol 2007;37(3):171-175

32 Buerki S, Roellin K, Remonda L, et al. Neuroimaging in childhood arterial ischaemic stroke: evaluation of imaging modalities and aetiologies. Dev Med Child Neurol 2010;52(11):1033-1037

33 Jones BP, Ganesan V, Saunders DE, Chong WK. Imaging in childhood arterial ischaemic stroke. Neuroradiology 2010;52(6):577589

34 Bash S, Villablanca JP, Jahan R, et al. Intracranial vascular stenosis and occlusive disease: evaluation with $\mathrm{CT}$ angiography, MR angiography, and digital subtraction angiography. AJNR Am J Neuroradiol 2005;26(5):1012-1021

35 Shah GV, Quint DJ, Trobe JD. Magnetic resonance imaging of suspected cervicocranial arterial dissections. J Neuroophthalmol 2004;24(4):315-318

36 Provenzale JM, Sarikaya B. Comparison of test performance characteristics of MRI, MR angiography, and CT angiography in the diagnosis of carotid and vertebral artery dissection: a review of the medical literature. AJR Am J Roentgenol 2009;193(4):1167-1174

37 Nebelsieck J, Sengelhoff C, Nassenstein I, et al. Sensitivity of neurovascular ultrasound for the detection of spontaneous cervical artery dissection. J Clin Neurosci 2009;16(1):79-82

38 Amlie-Lefond C, Bernard TJ, Sébire G, et al; International Pediatric Stroke Study Group.Predictors of cerebral arteriopathy in children with arterial ischemic stroke: results of the International Pediatric Stroke Study. Circulation 2009;119(10):1417-1423

39 Fullerton HJ, Wu YW, Sidney S, Johnston SC. Risk of recurrent childhood arterial ischemic stroke in a population-based cohort the importance of cerebrovascular imaging. Pediatrics 2007;119 (3):495-501

40 Mallick AA, O'Callaghan FJ. Risk factors and treatment outcomes of childhood stroke. Expert Rev Neurother 2010;10(8):1331-1346

41 Chabrier S, Lasjaunias P, Husson B, Landrieu P, Tardieu M. Ischaemic stroke from dissection of the craniocervical arteries in childhood: report of 12 patients. Eur J Paediatr Neurol 2003;7 (1): $39-42$

42 Guillon B, Bousser MG. [Epidemiology and pathophysiology of spontaneous cervical artery dissection]. J Neuroradiol 2002;29 (4):241-249

43 Lotze TE, Paolicchi J. Vertebral artery dissection and migraine headaches in children. J Child Neurol 2000;15(10):694-696

44 Smith ER, Scott RM. Moyamoya: epidemiology, presentation, and diagnosis. Neurosurg Clin N Am 2010;21(3):543-551

45 Hajj-Ali RA, Singhal AB, Benseler S, Molloy E, Calabrese LH. Primary angiitis of the CNS. Lancet Neurol 2011;10(6):561-572 
46 Amlie-Lefond C, Fullerton HJ. Rashes, sniffles, and stroke: a role for infection in ischemic stroke of childhood. Infect Disord Drug Targets 2010;10(2):67-75

47 Bernard TJ, Fenton LZ, Apkon SD, et al. Biomarkers of hypercoagulability and inflammation in childhood-onset arterial ischemic stroke. J Pediatr 2010;156(4):651-656

48 Amlie-Lefond C, Jubelt B. Neurologic manifestations of varicella zoster virus infections. Curr Neurol Neurosci Rep 2009;9(6):430434

49 Askalan R, Laughlin S, Mayank S, et al. Chickenpox and stroke in childhood: a study of frequency and causation. Stroke 2001;32 (6):1257-1262

50 Berger TM, Caduff JH, Gebbers JO. Fatal varicella-zoster virus antigen-positive giant cell arteritis of the central nervous system. Pediatr Infect Dis J 2000;19(7):653-656

51 Riou EM, Amlie-Lefond C, Echenne B, Farmer M, Sébire G. Cerebrospinal fluid analysis in the diagnosis and treatment of arterial ischemic stroke. Pediatr Neurol 2008;38(1):1-9

52 Wang JJ, Jiang LQ He B, Shi KL, Li JW, Zou LP. The association of CTLA-4 and CD28 gene polymorphisms with idiopathic ischemic stroke in the paediatric population. Int J Immunogenet 2009;36 (2):113-118

53 Enenstein J, Milbauer L, Domingo E, et al. Proinflammatory phenotype with imbalance of KLF2 and RelA: risk of childhood stroke with sickle cell anemia. Am J Hematol 2010;85(1):18-23

54 McQuillen PS, Barkovich AJ, Hamrick SE, et al. Temporal and anatomic risk profile of brain injury with neonatal repair of congenital heart defects. Stroke 2007;38(2, Suppl)736-741

55 Testai FD, Gorelick PB. Inherited metabolic disorders and stroke part 1: Fabry disease and mitochondrial myopathy, encephalopathy, lactic acidosis, and strokelike episodes. Arch Neurol 2010;67 (1):19-24

56 Testai FD, Gorelick PB. Inherited metabolic disorders and stroke part 2: homocystinuria, organic acidurias, and urea cycle disorders. Arch Neurol 2010;67(2):148-153

57 Bernard TJ, Manco-Johnson MJ, Goldenberg NA. et al. The roles of anatomic factors, thrombophilia, and antithrombotic therapies in childhood onset arterial ischemic stroke. Thromb Res 2010

58 Kenet G, Lütkhoff LK, Albisetti M, et al.Impact of thrombophilia on risk of arterial ischemic stroke or cerebral sinovenous thrombosis in neonates and children: a systematic review and meta-analysis of observational studies. Circulation 2010;121:1795-1797

59 Lippi G, Franchini M, Montagnana M, Salvagno GL, Targher G, Guidi GC. Inherited and acquired risk factors for arterial ischemic stroke in childhood. J Thromb Thrombolysis 2009;27(2): 239-248

60 Nowak-Göttl U, Langer C, Bergs S, Thedieck S, Sträter R, Stoll M. Genetics of hemostasis: differential effects of heritability and household components influencing lipid concentrations and clotting factor levels in 282 pediatric stroke families. Environ Health Perspect 2008;116(6):839-843

61 Munot P, De Vile C, Hemingway C, Gunny R, Ganesan V. Severe iron deficiency anaemia and ischaemic stroke in children. Arch Dis Child 2011;96(3):276-279

62 Hubail Z, Lemler M, Ramaciotti C, Moore J, Ikemba C. Diagnosing a patent foramen ovale in children: is transesophageal echocardiography necessary? Stroke 2011;42(1):98-101

63 Ramaswamy V, Mehta V, Bauman M, Richer L, Massicotte P, Yager JY. Decompressive hemicraniectomy in children with severe is- chemic stroke and life-threatening cerebral edema. J Child Neurol 2008;23(8):889-894

64 Smith SE, Kirkham FJ, Deveber G, et al.Outcome following decompressive craniectomy for malignant middle cerebral artery infarction in children. Dev Med Child Neurol 2011;53(1):29-3310.1111/ j.1469-8749.2010.03775.x

65 Amlie-Lefond C, Chan AK, Kirton A, et al; Thrombolysis in Pediatric Stroke (TIPS) Investigators.Thrombolysis in acute childhood stroke: design and challenges of the thrombolysis in pediatric stroke clinical trial. Neuroepidemiology 2009;32(4):279-286

66 Arnold M, Steinlin M, Baumann A, et al.Thrombolysis in childhood stroke: report of 2 cases and review of the literature. Stroke 2009;40(3):801-807

67 Grunwald IQ, Walter S, Shamdeen MG, et al.New mechanical recanalization devices - the future in pediatric stroke treatment? J Invasive Cardiol 2010;22(2):63-66

68 Bernard TJ, Goldenberg NA, Tripputi M, et al. Anticoagulation in childhood-onset arterial ischemic stroke with non-moyamoya arteriopathy: Findings from the Colorado and German (COAG) collaboration. Stroke 2009

69 Goldenberg NA, Bernard TJ, Fullerton HJ, Gordon A, deVeber G; International Pediatric Stroke Study Group.Antithrombotic treatments, outcomes, and prognostic factors in acute childhood-onset arterial ischaemic stroke: a multicentre, observational, cohort study. Lancet Neurol 2009;8(12):1120-1127

70 Bigi S, Fischer U, Wehrli E, et al.Acute ischemic stroke in children versus young adults. Ann Neurol 2011;70(2):245-254

71 Christerson S, Strömberg B. Stroke in Swedish children II: longterm outcome. Acta Paediatr 2010;99(11):1650-1656

72 Daseking M, Petermann F, Simonis A. [Behavioral disorders and psycho-social outcome after stroke in children]. Fortschr Neurol Psychiatr 2008;76(11):662-671

73 Eikelmann A, Petermann F, Daseking M. [Attention deficit disorders after stroke in childhood]. Z Kinder Jugendpsychiatr Psychother 2008;36(6):419-426

74 Everts R, Pavlovic J, Kaufmann F, et al.Cognitive functioning, behavior, and quality of life after stroke in childhood. Child Neuropsychol 2008;14(4):323-338

75 Westmacott R, Askalan R, MacGregor D, Anderson P, Deveber G. Cognitive outcome following unilateral arterial ischaemic stroke in childhood: effects of age at stroke and lesion location. Dev Med Child Neurol 2010;52(4):386-393

76 Domi T, deVeber G, Shroff M, Kouzmitcheva E, MacGregor DL, Kirton A. Corticospinal tract pre-wallerian degeneration: a novel outcome predictor for pediatric stroke on acute MRI. Stroke 2009;40(3):780-787

77 Ganesan V, Prengler M, Wade A, Kirkham FJ. Clinical and radiological recurrence after childhood arterial ischemic stroke. Circulation 2006;114(20):2170-2177

78 Eleftheriou D, Ganesan V. Controversies in childhood arterial ischemic stroke and cerebral venous sinus thrombosis. Expert Rev Cardiovasc Ther 2009;7(7):853-861

79 Härtel C, Schilling S, Sperner J, Thyen U. The clinical outcomes of neonatal and childhood stroke: review of the literature and implications for future research. Eur J Neurol 2004;11(7): 431-438

80 Pavlovic J, Kaufmann F, Boltshauser E, et al.Neuropsychological problems after paediatric stroke: two year follow-up of Swiss children. Neuropediatrics 2006;37(1):13-19 